\title{
Flexible Intramedullary Nailing for Paediatric Shaft of Femur Fractures - Does the Number of Nails Alter the Outcome?
}

\author{
B Kanthimathi, DNB Orth, K Arun Kumar, MS Orth \\ Division Of Orthopaedics, Annamalai University, Chidambaram, India
}

\begin{abstract}
Background: The use of flexible intramedullary nailing, allowing micro movement at the fracture site, results in excellent outcomes regardless of the number of nails used. We undertook analysis of the outcomes of flexible nailing with reference to the number of nails used. Methods: Twenty patients with diaphyseal femur fracture aged 5-15 years were treated with retrograde flexible intramedullary nailing. The number of nails varied from single to multiple. The results were analysed with regard to the number of nails used. Results: The mean patient age was 7.9 years; patients were followed up for a mean duration of 13.2 months. Those with two and three nails had similar results. Conclusion: A minimum of two flexible nails is needed for optimal fixation in paediatric femur shaft fractures. Also, limiting the number of implants to two is cost effective, decreases operative time, reduces radiation exposure and offers equal results to that of three nails.
\end{abstract}

Key Words:

Paediatric Femur Fracture, Flexible Intramedullary Nailing, Number of Nails

\section{INTRODUCTION}

Presently, flexible intramedullary nailing is the preferred treatment of choice for femur shaft fractures in patients aged 5-15 years. The technique is minimally invasive, relatively simple, and offers adequate stability and attributes to early mobilisation, early weight bearing and a faster recovery for the patient. Excellent results have been seen in terms of functional outcome and osseous union while use of the cumbersome plaster spica or prolonged traction is avoided. The most stability offered by flexible nailing occurs when adequate three point fixation is achieved. The flexible nail bends, hitching against the opposite cortex when inserted from one end and the apex of the bend should optimally be at the fracture site. The far end of the nail is contoured so that it lies opposite to the bend,resulting in trifocal buttressing in the medullary cavity. The second nail counteracts the buttressing of the other nail and offers the desired stability.
This technique allows micro movement at the fracture site leading to excellent callus formation. The idea of stacking the medullary cavity with more nails is believed to add stability to the reduction. The ultimate result of flexible intramedullary nailing is typically excellent and has its own advantages ${ }^{1-5}$. This study was undertaken to correlate the results of flexible intramedullary nailing for paediatric femur shaft fractures with the number of nails used.

\section{MATERIALS AND METHODS}

Study sample

Twenty paediatric patients (age range: 5-15 y) with diaphyseal femoral fractures of various patterns who were treated with flexible intramedullary nailing through retrograde technique in the year 2010 were selected for the study. Selection was based on the age of the child and location of the fracture in femur. Inclusion criteria were: 1) femoral shaft fractures; 2) aged 5-15 years; 3) diaphyseal fractures; and 4) closed fractures. Exclusion criteria were: 1) age below 5 years or above 15 years; 2) proximal and distal fractures; or, 3) compound and segmental fractures. All patients had a history of significant fall, mostly following a road traffic accident ${ }^{6}$. The sample was evenly divided between girls and boys and the mean age was 7.9 years; there was a diaphyseal fracture of the right femur in 9 patients and the left femur in 11 patients.

\section{Methods}

All the children were stabilised medically and evaluated for associated injuries. After temporary immobilisation of the fracture, standard anteroposterior and lateral radiographs were taken (Figure 1a, 2a and 3a). The fracture pattern was classified as transverse, oblique and spiral. There were no other complications and all underwent surgery within three days of injury.

Pre operative radiographs were measured for canal diameter; the mean diameter was $6.7 \mathrm{~mm}$ and nail sizes were selected accordingly. The size and the number of nails used were calculated according to the formula given by Flynn et al as well as intra operative assessment ${ }^{7}$. The diameter of nail was 
Table I: Results

\begin{tabular}{|c|c|c|c|c|c|c|c|c|c|}
\hline $\begin{array}{l}\text { Age/ } \\
\text { Gender }\end{array}$ & Type & $\begin{array}{c}\text { Canal } \\
\text { Diameter } \\
(\mathbf{c m})\end{array}$ & $\begin{array}{l}\text { Type of } \\
\text { Surgery }\end{array}$ & $\begin{array}{c}\text { No. of } \\
\text { nails }\end{array}$ & Union & $\begin{array}{l}\text { LLD } \\
(\mathrm{cm})\end{array}$ & $\begin{array}{c}\text { Angulation } \\
\text { (Degrees) }\end{array}$ & $\begin{array}{c}\text { Full weight } \\
\text { bearing } \\
\text { (Weeks) }\end{array}$ & Results \\
\hline $5 / \mathrm{M}$ & $\mathrm{S}$ & 6 & OR & 1 & 9 & 2 & $10^{\circ}$ varus & 12 & $P$ \\
\hline $5 / \mathrm{M}$ & $\mathrm{T}$ & 6 & CR & 2 & 7 & - & - & 11 & $E$ \\
\hline $6 / F$ & $\mathrm{O}$ & 6 & CR & 2 & 7 & - & - & 10 & $\mathrm{E}$ \\
\hline $6 / F$ & $\mathrm{~T}$ & 6 & CR & 2 & 8 & - & - & 10 & $\mathrm{E}$ \\
\hline $6 / F$ & $\mathrm{~T}$ & 6 & CR & 2 & 8 & 1 & - & 10 & $S$ \\
\hline $6 / F$ & $\mathrm{O}$ & 7 & CR & 3 & 8 & - & - & 11 & $S$ \\
\hline $6 / \mathrm{M}$ & $\mathrm{T}$ & 7 & CR & 3 & 8 & - & - & 10 & $S$ \\
\hline $7 / F$ & $\mathrm{O}$ & 6 & CR & 2 & 8 & - & - & 10 & $\mathrm{E}$ \\
\hline $7 / F$ & $\mathrm{O}$ & 7 & CR & 3 & 7 & - & - & 10 & $\mathrm{E}$ \\
\hline 7/M & $S$ & 7 & OR & 2 & 8 & 1 & - & 10 & $S$ \\
\hline 7/M & $\mathrm{T}$ & 6 & $C R$ & 3 & 8 & 1 & - & 11 & $S$ \\
\hline $8 / F$ & $\mathrm{~T}$ & 7 & CR & 2 & 8 & - & - & 10 & $\mathrm{E}$ \\
\hline $8 / \mathrm{M}$ & $S$ & 7 & OR & 1 & 9 & 2 & - & 11 & $P$ \\
\hline $8 / \mathrm{M}$ & $\mathrm{T}$ & 7 & CR & 2 & 8 & - & - & 10 & $\mathrm{E}$ \\
\hline 9/F & 0 & 6 & CR & 2 & 8 & 1.5 & - & 10 & $S$ \\
\hline $9 / F$ & $\mathrm{O}$ & 7 & CR & 3 & 7 & - & - & 10 & $\mathrm{E}$ \\
\hline 9/M & $\mathrm{T}$ & 7 & CR & 2 & 7 & - & - & 10 & $\mathrm{E}$ \\
\hline 11/M & $\mathrm{T}$ & 7 & OR & 3 & 7 & - & - & 10 & $\mathrm{E}$ \\
\hline $13 / \mathrm{M}$ & 0 & 8 & OR & 1 & 8 & 2 & - & 10 & $P$ \\
\hline 15/M & 0 & 8 & CR & 3 & 8 & - & - & 10 & $\mathrm{E}$ \\
\hline
\end{tabular}

KEY-

T- Transverse, O- oblique, S- Spiral, CR-Closed Reduction, OR- Open Reduction, LLD- Limb Length Discrepancy, E- Excellent, S- Satisfactory, P- Poor.

set as equal to the width of the narrowest point of the medullary canal on anteroposterior and lateral view x 0.4 $\mathrm{mm}$.

All nails were inserted in a retrograde manner through a minimal incision avoiding the physis. Advancement of nails into the proximal fragment was attempted and was guided by an image intensifier; this was successful in 15 patients. In the remaining 5 patients, an open reduction was performed. A minimum of two nails, mostly 2.5 and $3 \mathrm{~mm}$, were used in most patients. In a few cases, a third nail was utilised to fill the medullary cavity. Ultimately, 10 patients had two nails, 7 of them had 3 nails and 3 had a single nail. All reductions were satisfactory intraoperatively.

Range of motion exercises for the hip and knee were initiated mid first week postoperatively; for most patients, this was well tolerated except for the ones in which a single nail was used. The three patients with a single nail were put on skin traction during the early postoperative period. The mean duration of hospitalisation was seven days. Sutures were removed for all on the $12^{\text {th }}$ postoperative day. The mean duration of follow up was 13.2 months. Patients were reviewed periodically (every two weeks) for the assessment of radiological union and functional outcome until normal activity was regained.Results were evaluated using the Flynn et al scoring system and correlated to the number of nails used $^{8}$. Informed consent was obtained from the parents prior to inclusion in the study.
The study was reviewed by the appropriate ethics committee and was been performed in accordance with the ethical standards of the most recent version of the 1964 Declaration of Helsinki.

\section{RESULTS}

Pre-operative radiographs revealed fracture of the middle third of the shaft involvement in 12 patients, proximal and middle third junction in 7 patients, and middle and distal third junction in 1 patient. Postoperative radiographs were satisfactory in all patients except for the ones who had difficult reduction and single nail fixation (Figure $1 b, 2 b$ and $3 b$ ). Limb length inequalities of $2 \mathrm{~cm}$ were noted clinically in those with a single nail. Measurement was taken from the anterior superior iliac spine to the medial malleolus on the affected side and compared to the uninjured side. Children with a single nail were put on skin traction for the first two weeks. One child had a varus angulation of ten degrees.

Rotational malalignment was assessed clinically by comparing the internal and external rotation of both hips. We found no malalignment in any of the patients. All patients with two and three nails had a satisfactory reduction and a normal limb length that was well maintained during the postoperative period.

Functional assessments were conducted during the second postoperative week; seventeen patients showed full range of 


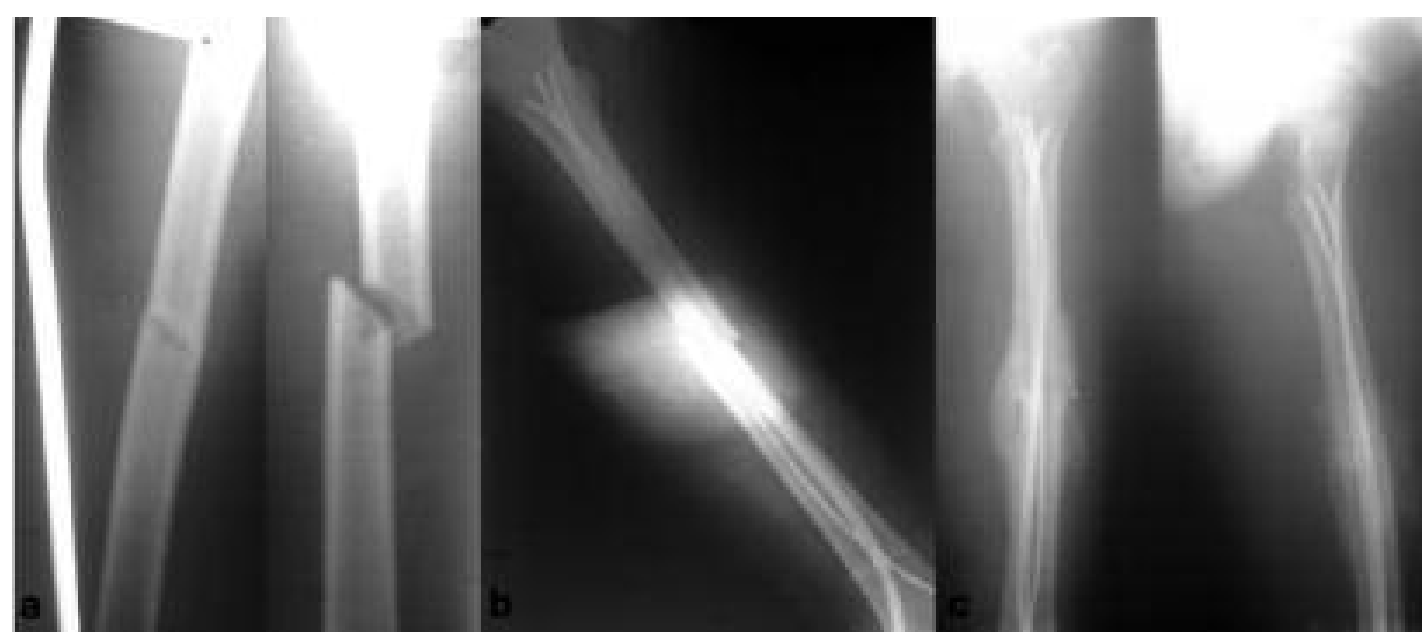

Fig. 1: (a) Pre operative radiograph, (b) Post operative radiograph with three nails in situ, (c) Radiograph showing union.
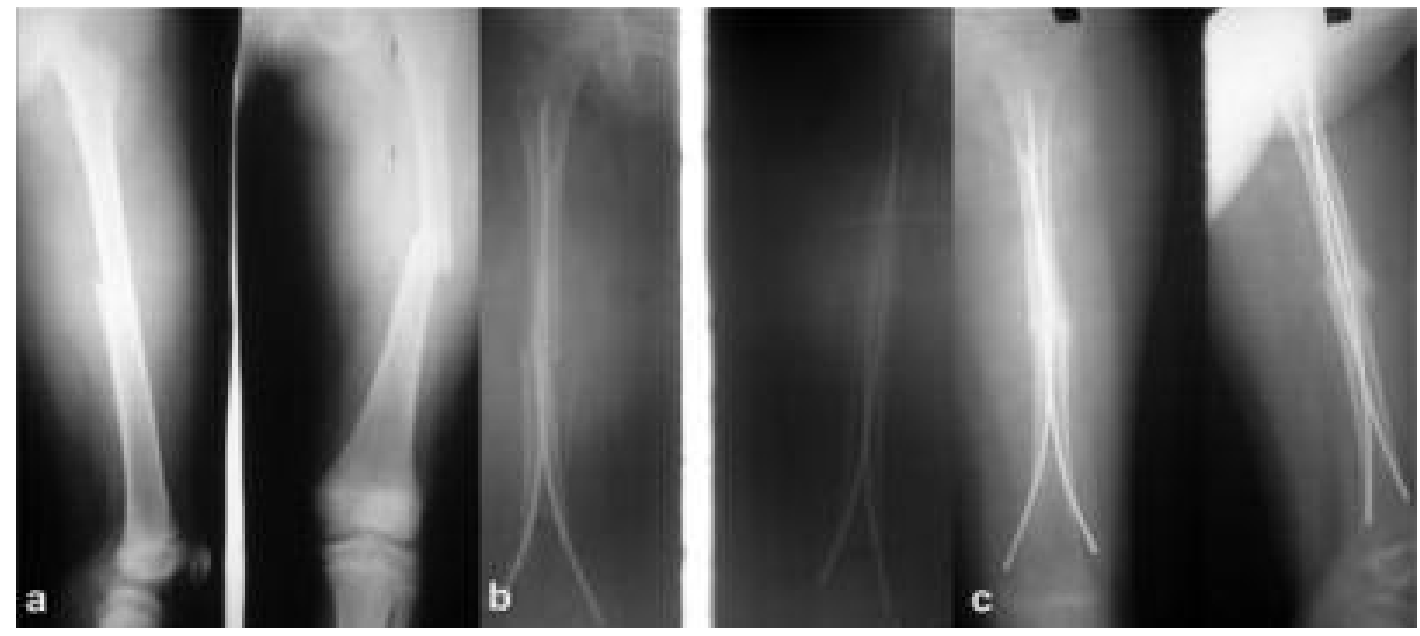

Fig. 2: (a) Pre operative radiograph, (b) Post operative radiograph with two nails in situ, (c) Radiograph showing union.

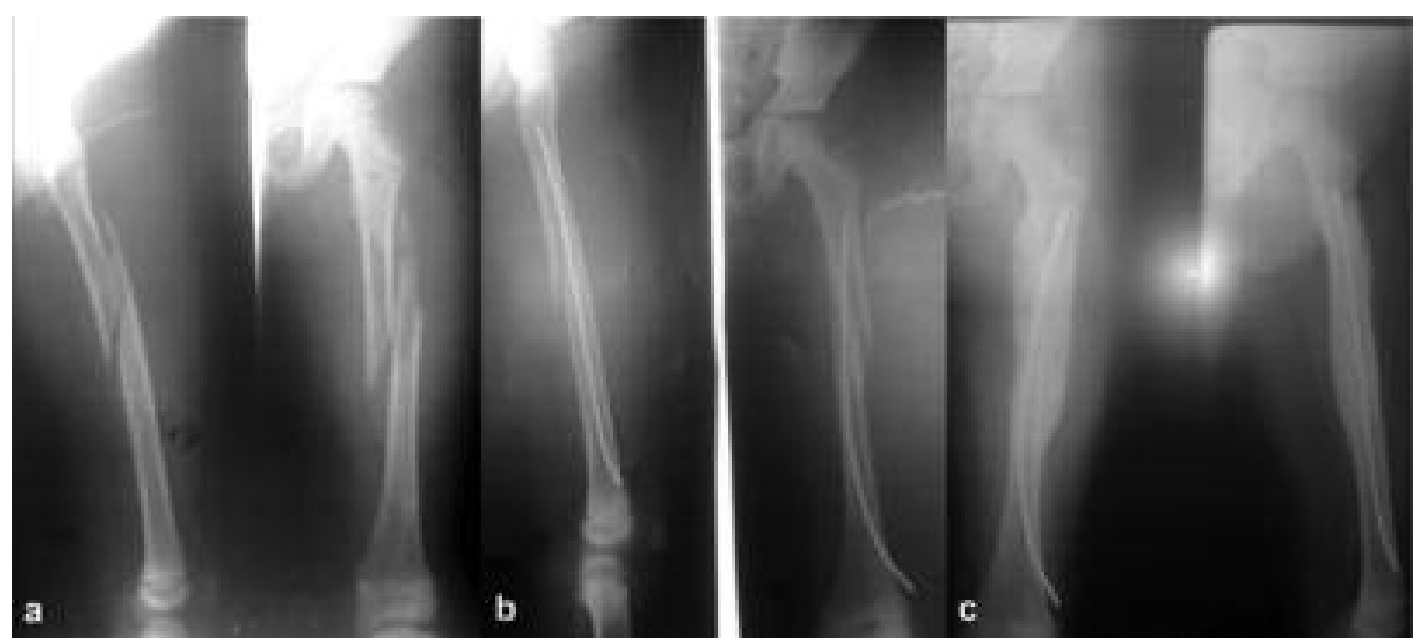

Fig. 3: (a) Pre operative radiograph, (b) Post operative radiograph with single nail in situ, (c) Radiograph showing union. 
movements of the hip and more than 90 degree active flexion of the knee joint. On further flexion, pain was limited to the entry site and this was gradually overcome by the patients. Range of movement exercises were started by mid second week for the patients who were on skin traction. They managed less than $90^{\circ}$ flexion of the knee by the end of the second week,but this too improved later on.

By four weeks, all had a complete range of motion in both hip and knee and the radiographs revealed callus formation around the fracture. For four patients with more than one, late collapse was observed in follow-up radiographs taken at 4 to 6 weeks,a insignificant finding. There was no muscle atrophy or immediate or late onset of infectious complications. There were no cases of skin irritation due to nails. Radiological union was seen at a mean duration of 7.8 weeks (Figure 1c, $2 \mathrm{c}$ and $3 \mathrm{c}$ ). Union occurred at 9 weeks in 2 patients where a single nail was used.

On union, a significant shortening of $2 \mathrm{cms}$ was seen in 2 patients where a single nail was used. There was shortening of $1 \mathrm{~cm}$ in 4 of the remaining patients. After union, all patients were allowed to partial weight bear as tolerated and full weight bearing was started by the second week of union. Difficulty in weight bearing was encountered by those with shortening which was compensated soon after initiation of weight bearing. Due to the excellent remodelling capacity of young bone, return to normal activity was achieved in all patients by twelve weeks regardless of the number of nails used.

Results were tabulated according to the Flynn et al scoring criteria and were found to be excellent in $55 \%$, satisfactory in $30 \%$ and poor in $15 \%$ of patients (Table I). Upon categorisation according to the number of nails used, $71.4 \%$ of those with 3 nails and $70 \%$ of those with 2 nails had excellent results, $28.5 \%$ of those with 3 nails and $30 \%$ of those with 2 nails had satisfactory results. Poor results were seen only among those where a single nail was used.

\section{DISCUSSION}

Flexible intramedullary nailing is a widely used standard technique and has been proven to have advantages over other methods of treatment ${ }^{9,10}$. Biological fixation allows micro movement at the fracture site which enhances callus formation and hence is best suited for paediatric age group ${ }^{11}$. Stainless steel elastic nails, which were used previously, yield the same result as that of titanium nails ${ }^{12}$. The technique is minimally invasive and requires only a short hospital stay.

In addition to the positive properties for management of paediatric shaft of femur fractures, flexible intramedullary nailing entails certain difficulties and complications, which need to be studied ${ }^{13,14}$. The complication rate is higher in obese and overweight children ${ }^{15,16}$. Flexible nailing must also include adequate three point fixation when the apex of the bend is at the fracture site. Contouring the apex of the bend to be at the fracture site requires meticulous work and depends on the level at which the fracture lies in the shaft. On occasions when the contouring is not satisfactory, an additional nail is used to add stability to the reduction.

Our results show that the stability offered by a minimum of two nails is sufficient to stabilise the fracture in the paediatric age group, and results in the desired biological fixation so that the fracture can heal on its own. When limited to two nails, the results were excellent and cost effective as compared to the use of three nails. Use of an additional nail only prolongs the operative time, increases exposure to radiation and chances of infection, all of which should be avoided when possible. Final outcome were not different between cases where two or three nails are used. When adequate stability can be achieved with utilisation of two nails, there seems to be no reason why another nail should be inserted. With the enormous potential for healing of paediatric fractures, it is not necessary to fill the medullary cavity to its maximum.

Our results also demonstrate that a single elastic nail alone is not sufficient for treating a fractured femur and will mostly result in late collapse leading to shortening and angulations. Late collapse usually occurs when the mechanical forces acting at the fracture site exceed the stability offered by the nails. In our study, from the start of passive mobilisation up to full weight bearing, there was a delay in progress of approximately two weeks in those patients where single nail was used. Initial tolerance to full weight bearing was not as good in the single nail patients when compared to the remainder of the study sample. However, use of a single nail cannot be avoided when there is a comminuted fragment that would be displaced by the second nail.

Though all patients returned to normal activity by 12 weeks postoperatively, there were limb length discrepancies and angulations in the few cases where late collapse occurred. The limb length discrepancy and the residual angulations were well tolerated by the patients and all regained full function of the affected limb. However, a review at skeletal maturity will reveal whether limb length discrepancy and angulations remodelled completely or not. The overall results were $55 \%$ excellent, $30 \%$ satisfactory and $15 \%$ poor.

On analysis according to the number of nails used, we find that similar results were seen in those patients where two or three nails were used. Poor results were only seen in those cases where a single nail was used. We therefore conclude that using a minimum of two flexible nails in paediatric femur shaft fractures offers the desired biological fixation and adequate stability to hold the fracture. Further, we found that the use of two nails is optimal for the patient. Limiting 
oneself to the use of the minimum number of implants needed is more cost effective, decreases operating time, reduces radiation exposure and offers equal results as that of three nails.

\section{CONCLUSION}

The use of flexible intramedullary nailing in selective paediatric age group proves to be an effective modality of treatment. A single nail is inadequate for achievement of stable fixation whereas three nails are unnecessary. The insertion of two nails is sufficient to result in biological fixation and at the same time decreases the cost, operative time and radiation exposure. 


\section{REFERENCES}

1. Flynn JM, Hresko T, Reynolds RAK, Blasier D, Davidson R, Kasser J. Titanium Elastic Nails for Pediatric Femur Fracutes: A Multicenter Study of Early results with Analysis of Complications. J Pediatr Orthop 2001; 21:4-8.

2. Saikia KC, Bhuyan SK, Bhattacharya TD, Saikia SP. Titanium elastic nailing in femoral diaphyseal fractures of children in 6-16 years of age. Indian J Orthop 2007; 41: 381-5.

3. Singh R, Sharma SC, Magu NK, Singla A. Titanium elastic nailing in pediatric femoral diaphyseal fractures. Indian J Orthop 2006; 40: 29-34.

4. Khazzam M, Tassone C, Liu XC, Lyon R, Freeto B, Schwab J, et al. Use of Flexible Intramedullary Nail Fixation in Treating Femur Fractures in Children. Am J Orthop 2009; 38: E49-55.

5. Mortier D, De Ridder K. Flexible intramedullary nailing in the treatment of diaphyseal fractures of the femur in preschool children. Acta Orthop Belg 2008; 74: 190-4.

6. Bener A, Justham D, Azhar AA, Rysavy M, AI-Mulla F. Femoral fractures in children related to motor vehicle accidents. J Orthop Nurs 2007; 11: 146-50.

7. Flynn JM, Skaggs DL, Sponseller PD, Ganley TJ, Kay RM, Kellie Leitch KK. The operative management of pediatric fractures of the lower extremity. J Bone Joint Surg Am 2002; 84: 2288-300.

8. Flynn JM, Schwend RM. Management of pediatric femoral shaft fractures. J Am Acad Orthop Surg 2004;12:347-59.

9. Saseendar S, Menon J, Patro DK. Treatment of femoral fractures in children: is titanium elastic nailing an improvement over hip spica casting? J Child Orthop 2010; 4: 245-51.

10. Soo-Sung Park, Jae-Bum Park. Comparison of flexible intramedullary nailing with external fixation for treating pediatric femoral shaft fractures. J Korean Orthop Assoc 2008; 43: 665-71.

11. Yamaji T, Ando K, Nakamura T, Washimi O, Terada N, Yamada H. Femoral shaft fracture callus formation after intramedullary nailing: a comparison of interlocking and Ender nailing. J Orthop Sci 2002; 7: 472-6.

12. Shekhar L, Mayanger JC. A clinical study of Ender nails fixation in femoral shaft fractures in children. Indian J Orthop 2006; 40: 35-7.

13. Nitish Gogi, Shah Alam Khan, Manish K. Varshney. Limb length discrepancy following titanium elastic nailing in paediatric femoral shaft fractures. Acta Orthop Belg 2006; 72: 154-8.

14. Sagan, Michelle L. Residual Deformity After Treatment of Pediatric Femur Fractures With Flexible Titanium Nails. J Pediatr Orthop 2010; 30: 638-43.

15. Weiss JM, Choi P, Ghatan C, Skaggs DL, Kay RM. Complications with flexible nailing of femur fractures more than double with child obesity and weight $>50 \mathrm{~kg}$. $J$ Child Orthop 2009; 3: 53-8.

16. Li Y, Stabile KJ, Shilt JS. Biomechanical analysis of titanium elastic nail fixation in a pediatric femur fracture model. J Pediatr Orthop 2008; 28: 874-8. 